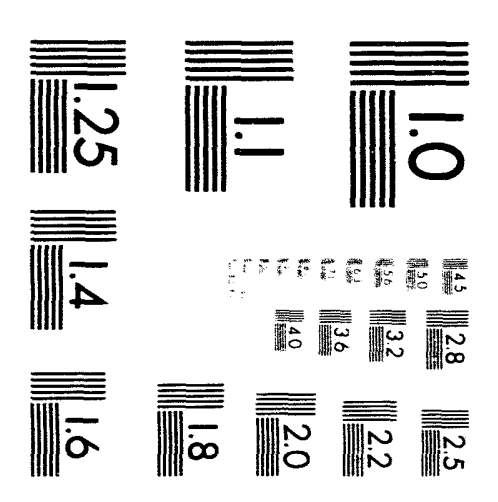



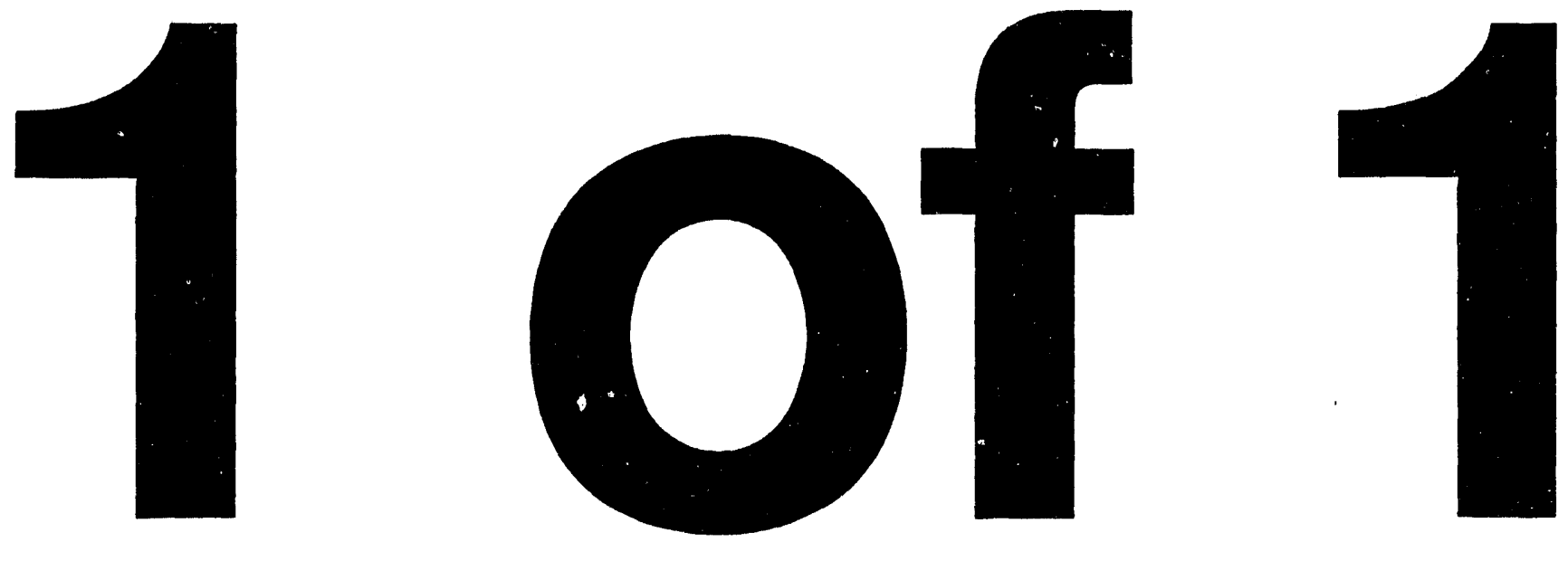


\title{
Pellet Injector Development and Experiments at ORNL *
}

\author{
L.R. Baylor, B.E. Argo, G.C. Barber, S.K. Combs, M.J. Cole, G.R. Dyer, \\ D.T. Fehling, P.W. Fisher, C.A. Foster, C.R. Foust, M.J. Gouge, T.C. Jernigan, \\ R.A. Langley, S.L. Milora, A.L. Qualls, D.E. Schechter, D.O. Sparks, C.C. Tsai, \\ J.B. Wilgen, J.H. Whealton
}

Oak Ridge National Laboratory, Oak Ridge, Tennessee 37831-8071, USA

\begin{abstract}
The development of pellet injectors for plasma fueling of magnetic confinement fusion experiments has been under way at Oak Ridge National Laboratory (ORNL) for the past 15 years. Recently, ORNL provided a tritium-compatible four-shot pneumatic injector for the Tokamak Fusion Test Reactor (TFTR) based on the in situ condensation technique that features three single-stage gas guns and an advanced two-stage light gas gun driver. In another application, ORNL supplied the Tore Supra tokamak with a centrifuge pellet injector in 1989 for pellet fueling experiments that has achieved record numbers of injected pellets into a discharge. Work is progressing on an upgrade to that injector to extend the number of pellets to 400 and improve pellet repeatability. In a new application, the ORNL three barrel repeating pneumatic injector has been returned from JET and is being readied for installation on the DIII-D device for fueling and enhanced plasma performance experiments.

In addition to these experimental applications, ORNL is developing advanced injector technologies, including high-velocity pellet injectors, tritium pellet injectors, and long-pulse feed systems. The two-stage light gas gun and electron-beam-driven rocket are the acceleration techniques under investigation for achieving high velocity. A tritium proof-of-principle (TPOP) experiment has demonstrated the feasibility of tritium pellet production and acceleration. A new tritium-compatible, extruder-based, repeating pneumatic injector is being fabricated to replace the pipe gun in the TPOP experiment and will explore issues related to the extrudability of tritium and acceleration of large tritium pellets. The tritium pellet formation experiments and development of long-pulse pellet feed systems are especially relevant to the International Tokamak Engineering Reactor (ITER).
\end{abstract}

\section{$\underline{\text { Introduction }}$}

Steady progress has been made in the past several years at ORNL in the development and application of pellet injectors for fueling present-day and future magnetic confinement fusion devices $[1,2]$. The recent emphasis has been in the areas of (1) tritium pellet injector development in support of TFTR deuterium-tritium (DT) operation, (2) long pulse centrifuge pellet injector development for Tore Supra and ITER high throughput applications, (3) modification of the JET repeating pneumatic pellet injector for installation on DIII-D, (4) repeating two-stage light gas gun development (for anticipated higher speed ITER application at 2.5-5 $\mathrm{km} / \mathrm{s}$ ), and (5) e-beam rocket accelerator concept for future ultrahigh-speed applications. In this paper we describe recent developments and experimental applications with emphasis on items 1-3. A program to upgrade the present ORNL centrifuge injector technology to longer pulse operation (up to 400 pellets per discharge) is described by Foster et al. [3]. A collaboration between ORNL and ENEA-Frascati in the development of a repeating two-stage light gas gun based on an extrusion type pellet feed system is described by Combs et al. [4].

\section{Tritium Pellet Injector for TFTR}

The tritium pellet injector (TPI) for TFTR was built by ORNL and installed on TFTR in 1992, having been modified from the deuterium pellet injector (DPI) that was used on TFTR from 1986-1991. The TPI has a tritium fueling capability with pellet speeds in the 1 to $3 \mathrm{~km} / \mathrm{s}$ range for the TFTR DT phase of operation. The TPI shown in Fig. 1 has a four barrel pipe-gun configuration (in situ condensation technique) with three single-stage pneumatic guns that use a fast propellant valve and one two-stage light gas gun driver [5]. Two of the single-stage guns have $3.4 \mathrm{~mm}$ diameter barrels while the remaining two guns have $4 \mathrm{~mm}$ diameter barrels. The nominal pellet aspect ratio is 1.25 , but pellets can be formed in situ with aspect ratios that range from 1.0 to 1.5. The TPI has gaseous helium cooled cryostats that provide cooling for pellet formation and $\mathrm{He} 3$ separation.

The TPI was installed and commissioned on TFTR in 1992 and then used in the subsequent deuterium experimental run. The primary experiment that it has been

\footnotetext{
"Reseerch sponsored by the Office of FuYion Energy, U.S. Department of Energy, under contract DE-AC05-84OR21400 with Martin Marietta Energy Systems, Inc 


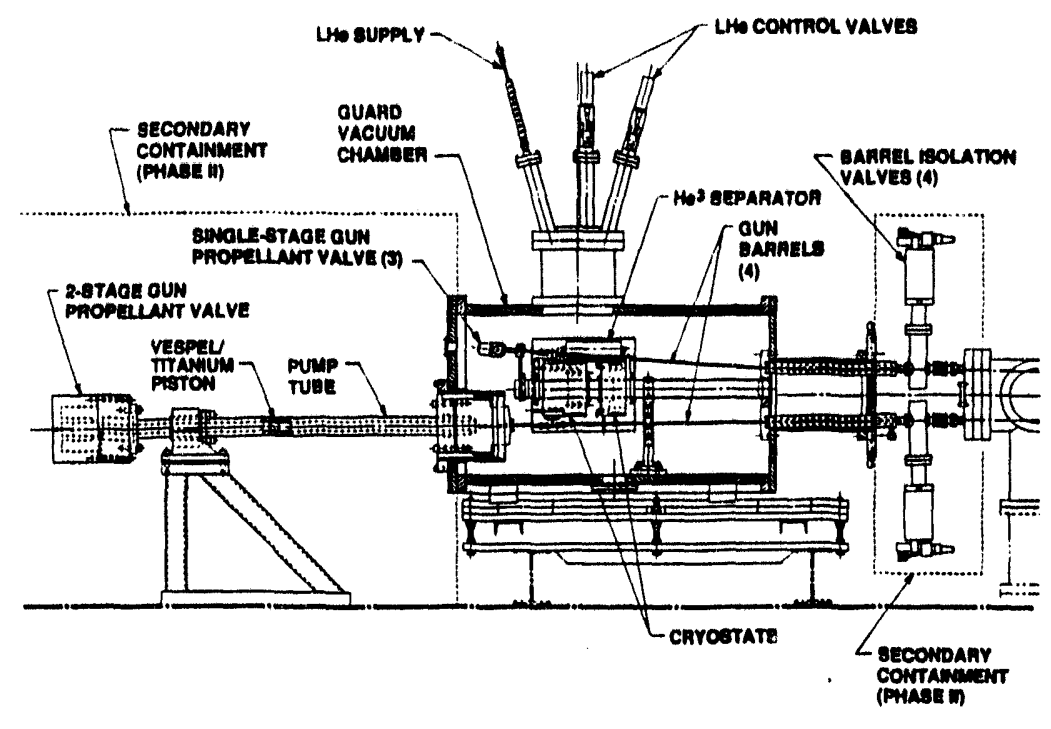

Fig. 1 TFTR tritium compatible four shot pellet injector (TPI).

used for to date is the exploration of the pellet enhanced performance (PEP) mode, where a strongly peaked density profile plasma is created by pellet injection as shown in Fig. 2 and heated with high power ion cyclotron resonance heating [6]. Single $4 \mathrm{~mm}$ pellets have been injected to the center of ohmic discharges and have generated strongly peaked density profiles with central densities in excess of $2 \mathrm{x}$ $10^{20} \mathrm{~m}^{-3}$. Up to $5 \mathrm{MW}$ of ICRH power (resonant on axis) has been applied to these dense plasmas resulting in an increased neutron yield and improved core confinement when compared to similar non-pellet discharges, thus indicating the attainment of a PEP mode. The neutron emission rate from these PEP mode experiments on TFTR is shown in Fig. 3 where the PEP neutron rate is found to be as much as 3

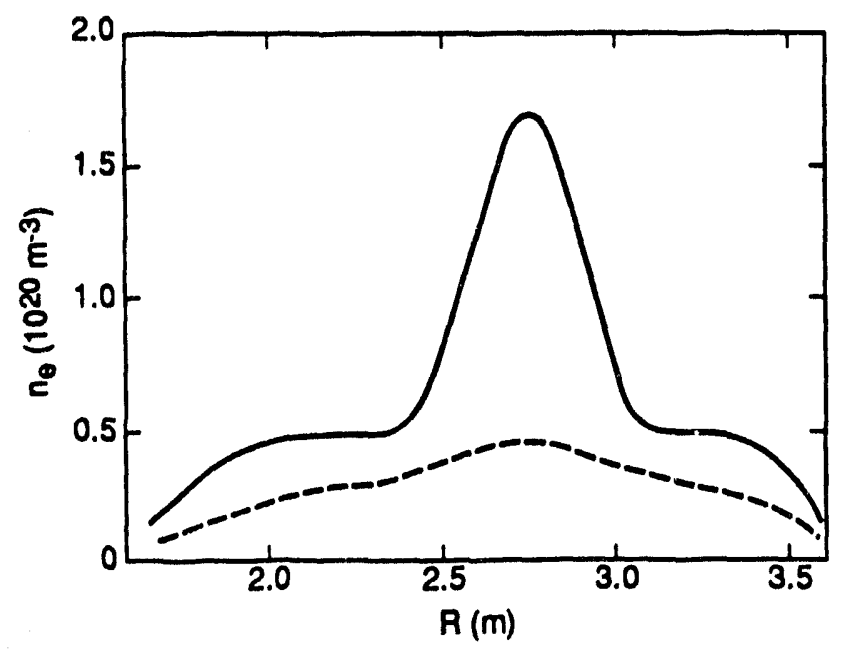

Fig 2 Electron density profiles for a TFTR PEP mode discharge (solid) and a similar non-PEP mode discharge (dashed). times higher than for non PEP discharges. The results of these experiments have been useful in helping to further understand the phenomenon of the PEP mode, which has the possible application of being used to aid the ignition startup phase for ITER. The TPI has also been used in other experiments including high velocity injection, where single pellets from the two stage gun were injected at speeds up to $2.2 \mathrm{~km} / \mathrm{s}$ into high power neutral beam heated discharges.

The TPI as installed on TFTR is fully tritium compatible and radiation hardened for TFTR DT operations. A DT gas manifold and two secondary containment structures remain to be fitted to the pellet injection system to provide full tritium pellet capability. Current plans call for deuterium pellet operation only during the TFTR DT phase.

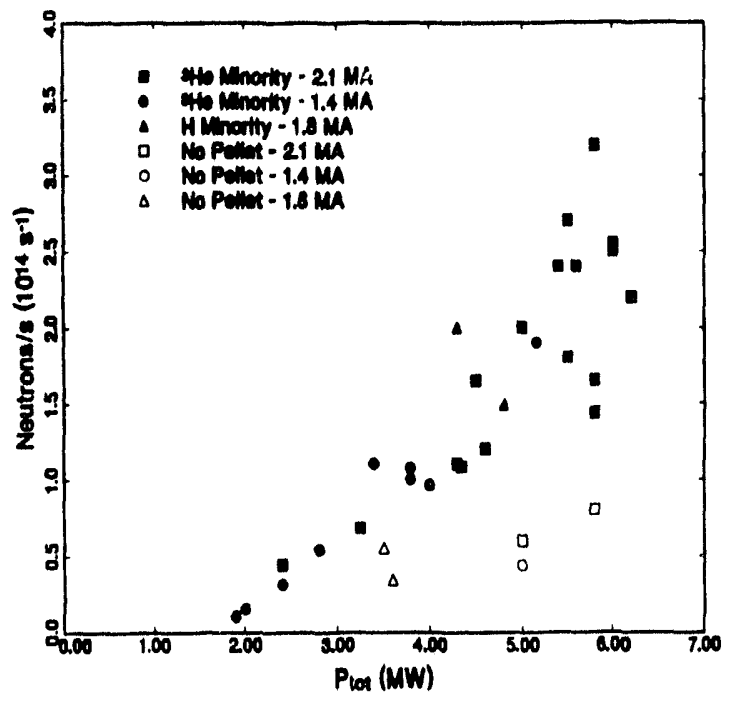

Fig. 3 Neutron production rate as a function of total input power for TFTR PEP and non-PEP discharges. 


\section{Eentrifuge Pellet Injector for Tore Supra}

A centrifuge pellet injector was developed at ORNL for long pulse fueling on Tore Supra and has been operating there since 1989 171. The injector presently has the capability to inject 100 pellets into a single plasma discharge but is being upgraded to produce up to 400 pellets with better repeatability of pellet size [4]. The injected pellet speeds are nominally $600 \mathrm{~m} / \mathrm{s}$ with sizes ranging from 4 to $12 \mathrm{mbar}-1$ per pellet $\left(2-7 \times 10^{20}\right.$ atoms per pellet).

In recent pellet fueling experiments on Tore Supra up to 79 pellets have been injected into 30 second long discharges, which is a record number of pellets injected into a tokamak. Successful fueling with pellet injection into plasmas with up to $2.5 \mathrm{MW}$ of lower hybrid current drive power has been achieved by suppressing the lower hybrid if power for a $50 \mathrm{~ms}$ window around the injection times [8]. An example of this type of experiment is shown in Fig. 4 where 20 pellets are injected during lower hybrid current drive in a plasma with a central electron temperature of $3 \mathrm{keV}$.

The goal at Tore Supra is to move toward steadystate operation with discharges lasting up to 2 minutes with active particle pumping and fueling. Therefore, the pellet feed system for the Tore Supra centrifuge injector is currently being upgraded to provide up to 400 pellets per plasma discharge. To accomplish this, deuterium is condensed on a rotating copper cylinder and scraped into four hemispherical rings of pellet material with an appropriately shaped tool. A cutting tool and punch mechanism driven by a computer controlled brushless DC servo system are then used to cut the pellets and place them in position at the centrifuge arbor at the correct time. The size of the pellets is variable by changing the position of the pellet cutting tool relative to the copper cylinder. Details of this upgrade design and the current status are described by Foster [3].

\section{Repeating Pneumatic Injector for DIII-D}

The three barrel repeating pneumatic injector that was previously used on the JET tokamak from 1987 to 1992 [9] is being readied for installation on DIII-D as shown in Fig. 5. The injector was used to inject over 3000 pellets into JET plasmas for fueling experiments while it was installed there and was found to have a high degree of reliability. For DIII-D, the barrel diameters will be $1.8,2.7$, and $4.0 \mathrm{~mm}$ (nominally $2.8 \times 10^{20}, 9 \times 10^{20}$, and $3 \times 10^{21}$ atoms per pellet) and capable of repetitive operation $(7.5,5$, and $2.5 \mathrm{~Hz}$, respectively) under quasi-steady-state conditions (>10 s). Since JET did not use a conventional pellet delivery system with guide tubes and differential pumping, these items are being provided for the installation on DIII-D. The pellet injection system for DIII-D, consisting of an injector stand, guide tubes, pellet diagnostics, differential vacuum pumping system, and computer control and data acquisition system, is being fabricated at ORNL for installation with the injector on DIII-D in 1994

The pellet injector on DIII-D will be used for advanced tokamak confinement studies such as the PEP mode experiments mentioned above, $\mathrm{H}$ and $\mathrm{VH}$-mode studies, and for fueling experiments in conjunction with the pumped divertor on DIII-D.

\section{Advanced Injector Technologies}

A collaboration between ORNL and ENEA-Frascati to develop a repeating two-stage pellet injector is currently under way at ORNL where testing of a prototype repeating injector with a two stage light gas gun driver has begun. The injector uses an ORNL hydrogen extruder equipped with a pellet chambering mechanism/gun barrel and a Frascati twostage light gas gun. The two devices have been mated together in the laboratory and are currently being used to accelerate deuterium pellets. Details of the initial results of these tests are described by Combs et al. [4].

The development of a tritium extruder for pellet injection is currently under way at ORNL. An 8-mm (ITERrelevant size), tritium-compatible, extruder based repeating pneumatic injector is being fabricated to replace the pipe gun device in the TPOP pellet injector [8]. The glove box, pumping systems, injection line, and pellet diagnostics from the original TPOP injector will be reused. The previous work with the TPOP injector verified that pure tritium and DT mixture pellets can be formed and accelerated to speeds up to $1.4 \mathrm{~km} / \mathrm{s}$. Operation of this new extruder based TPOP injector will explore issues related to the extrudability of tritium and acceleration of extruded tritium pellets. Tritium experiments with this gun are expected to begin at Los Alamos National Laboratory's Tritium Systems Test Assembly (TSTA) in 1994.

An electron-beam-heated rocket proof-of-principle apparatus is currently being used at ORNL to examine the possibility of using a focused electron beam applied to the solid hydrogen pellet surface to accelerate the pellet. Speeds up to $580 \mathrm{~m} / \mathrm{s}$ have been reached with $4 \mathrm{~mm}$ cryogenic hydrogen and deuterium pellets using a $10 \mathrm{kV}$ electron beam ( $0.2 \mathrm{~A}$ for $1 \mathrm{~ms})$. The limit of acceleration for hydrogenic pellets is found to correspond to an effective acceleration pressure of $0.2 \mathrm{MPa}$. To overcome this limit, a higher strength material such as lithium has been proposed as the propellant material. Initial tests with lithium and lithium hydride pellets as a propellant material at higher electron beam powers are under way.

A large part of future ORNL pellet injector development will be directed in support of the ITER project. The present high-velocity pellet injector development and tritium injector research are particularly relevant to ITER and future fusion reactors. Applications such as ITER will require long-pulse fueling; therefore, reliable steady state operation of pellet injection systems is a major objective of the ORNL 

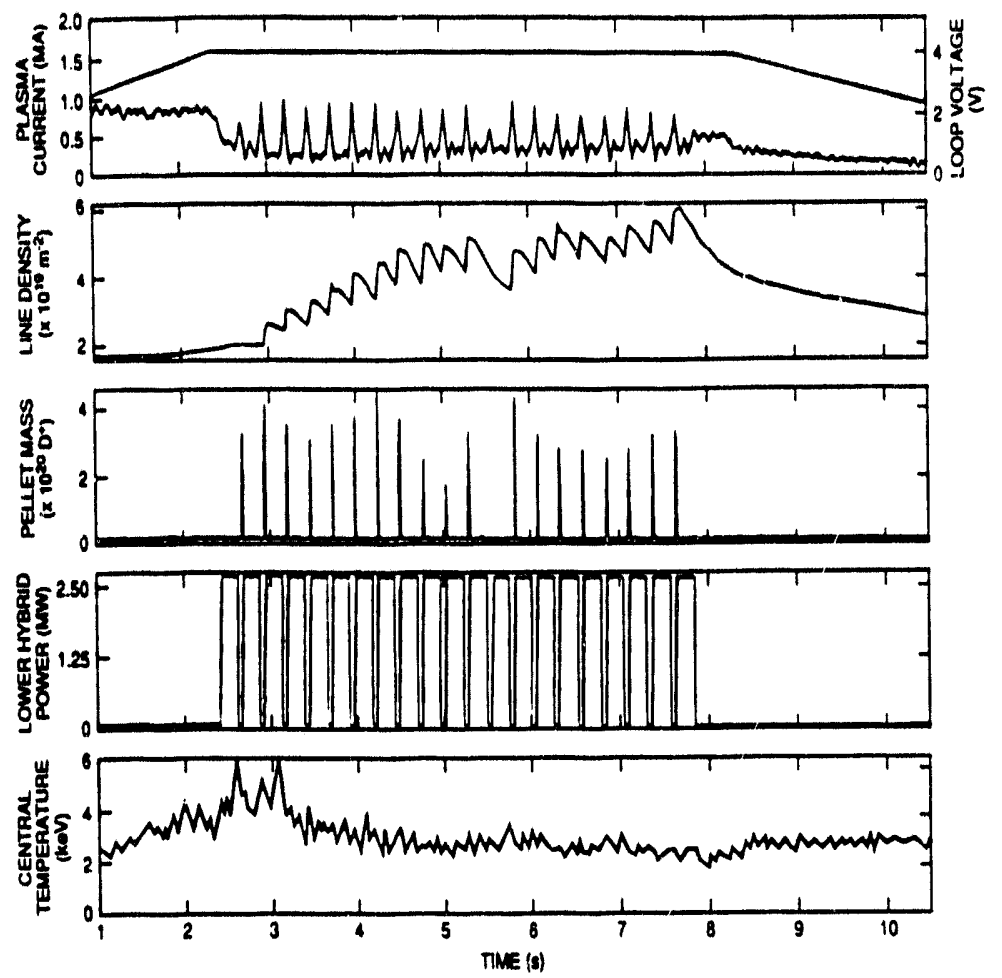

Fig. 4 Multiple pellet injection into a lower hybrid current drive discharge on Tore Supra.

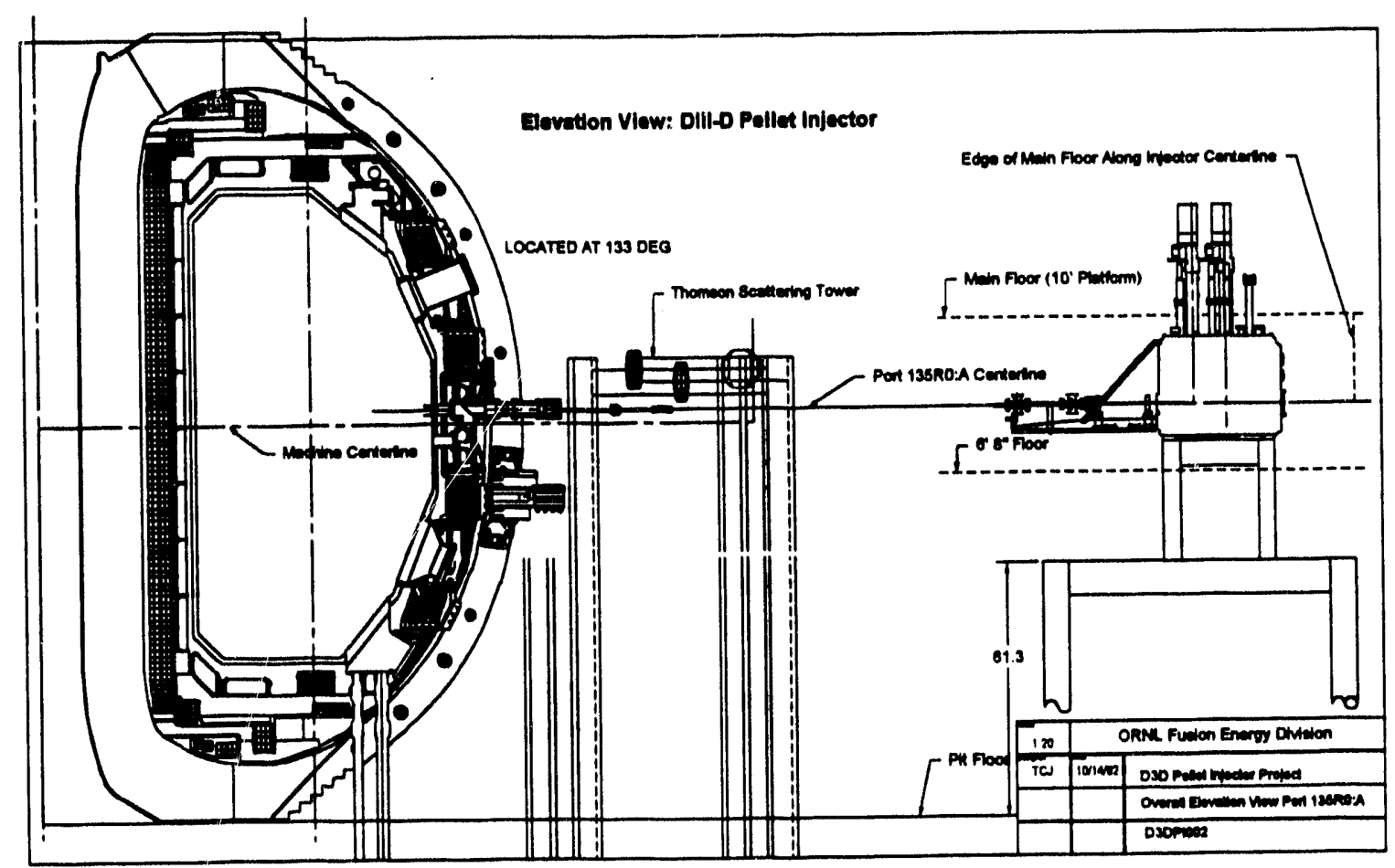

Fig. 5 Planned installation of three barrell repeating pneumatic injector on DIIl-D. 
program. The use of multiple identical extruders operating in tandem is one possible continuous source of hydrogen ice for steady-state operation. Another possibility is extending the pellet feed system being developed for the Tore Supra centrifuge injector to steady-state pellet fabrication. Development of these techniques is planned and such feed systems, combined with a reliable asceleration system, can form the basis for a steady-state pellet fueling system.

ITER and future fusion reactors will require a flexible plasma fueling capability with a mix of gas puffing and low- and high-velocity DT pellets to satisfy the multiple physics and engineering constraints of fusion power density, bum control, tritium burn fraction, edge density control, and gaseous divertor density for efficient plasma exhaust (including $\mathrm{He}$ ash) and protection of plasma-facing components. Pellet fueling offers the capability to influence the ITER core plasma, especially during startup with large high-velocity pellets, while lower velocity pellets allow isotopic tailoring of the various fueling sources and may provide more control of the tritium burn fraction and global tritium inventory.

A proposed pellet fueling system for ITER [12] is shown in plan view in Fig. 6. The system consists of three pellet injectors: a high-velocity two-stage light gas gun injector, a moderate-velocity single-stage light gas gun based a repeating pneumatic injector, and a centrifuge injector. The high-velocity and moderate-velocity injector will be used for ramp-up to ignition. during which the plasma density will continuously increase, while the centrifuge injector will provide continuous fueling in the steady-state burn phase. The centrifuge injector for steady-state fueling has the advantage of a small propellant gas load. which eliminates the need for a differential pumped injection line and the reprocessing requirements of a large propellant gas flow. All three injectors are designed for tritium operation and are housed in a shielded containment room.

\section{Summary}

In this paper, we have summarized the recent progress and status of pellet injection development and pellet fueling research activities at ORNL, including applications of recently developed injection systems on present large experimental devices such as TFTR, Tore Supra, and DIII-D. A large part of the future ORNL pellet injector development and experiments will be directed toward support of ITER and TPX, which will require more reliable and longer-pulse fueling capabilities than have been developed to date.

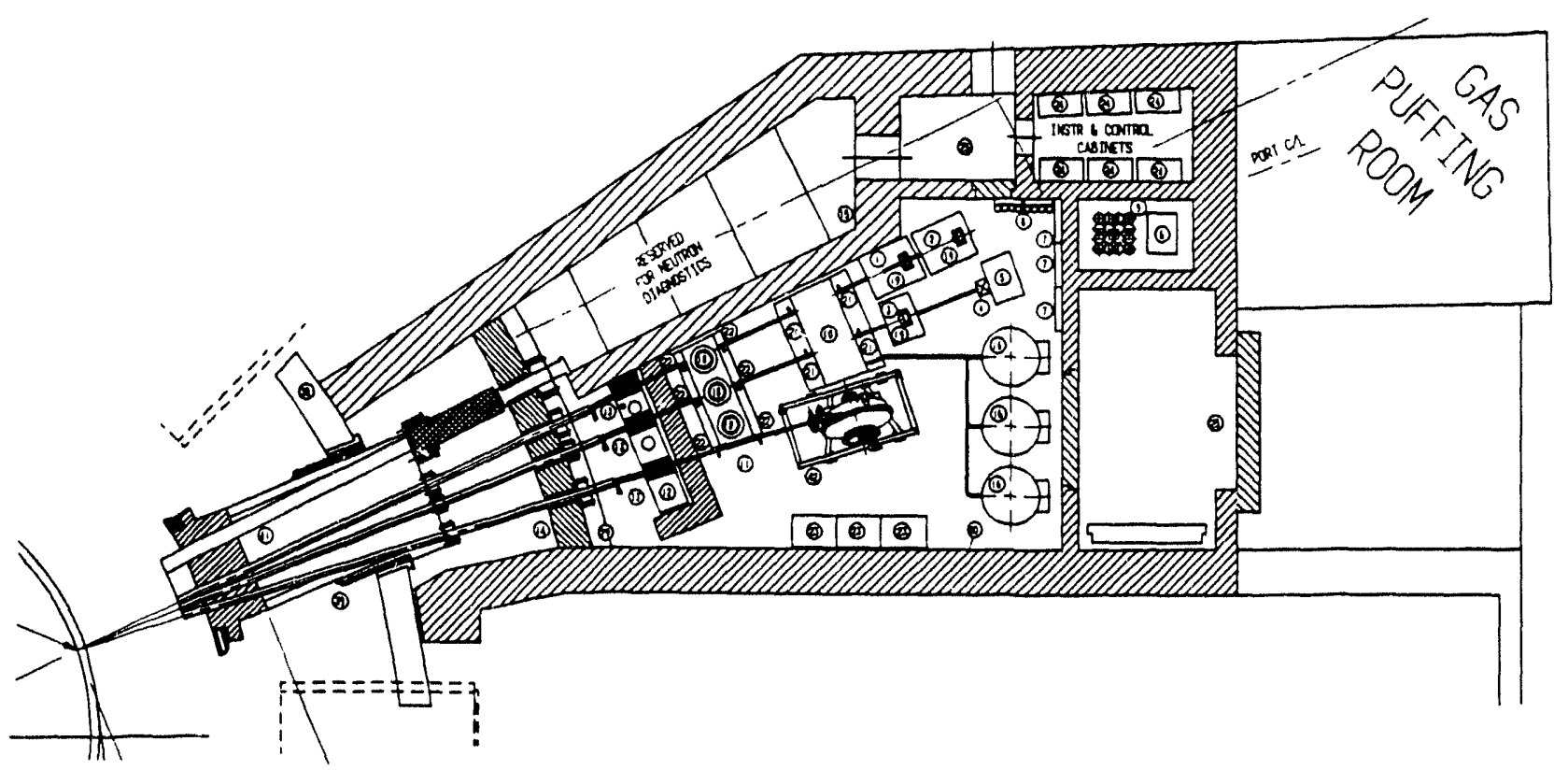

Fig. 6 Plan view of a conceptual pellet injection system for ITER. 


\section{$\underline{\text { References }}$}

[1] S. L. Milora, "Review of hydrogen pellet injection technology for plasma fueling applications," $J$. Vac. Sci. Technol. A, vol. 7, p. 925, 1989.

[2] S.K. Combs, "Pellet injection technology," Rev. Sci. Instrum., vol. 67, p. 1679, 1993.

[3] C.A. Foster, A.L. Qualls, L.R. Baylor, D.E. Schechter, S.L. Milora, "A 400 pellet feed system for the ORNL centrifuge pellet injector," these proceedings.

[4] S.K. Combs et al.,"High speed repetitive pellet injector for plasma fueling of magnetic confinement fusion devices," these proceedings.

[5] M.J. Gouge et al., "Pellet injection system for ITER," Fusion Technology, vol. 21, p. 1665, 1992.

[6] L.R. Baylor et al., to be submitted for publication in Nucl. Fusion, unpublished.
[7] C.A. Foster et al., "ORNL centrifuge pellet fueling system," presented at the 17th Symposium on Fusion Technology, Rome, Sep. 1992 (to be published).

[8] A. Geraud et al., in Contolled Fusion and Plasma Physics (Proc. 19th Eur. Conf. Innsbruck, 1992), vol 16C, Part I, European Physical Society, p. 159, 1992.

[9] S.K. Combs, S.L. Milora, L.R. Baylor, C.R. Foust, F.E. Gethers, D. O. Sparks, "A three-barrel repeating pneumatic pellet injector for plasma fueling of the Joint European Torus," J. Vac. Sci. Technol. A, vol. 6, p. $1901,1988$.

[10] S.K. Combs et al., "Performance of a pneumatic hydrogen-pellet injection system on the Joint European Torus," Rev. Sci. Instrum., vol. 60, p. 2697, 1989.

[11] P. W. Fisher, " Tritium proof - of - principle pellet injector," ORNL/TM-11781, Oak Ridge National Laboratory, 1991.

[12] M.J. Gouge, K.D. St. Onge, S.L. Milora, P.W. Fisher, S.K. Combs, "Pellet fueling system for ITER," Fusion Engineering and Design, vol. 19, p. 53, 1992. 

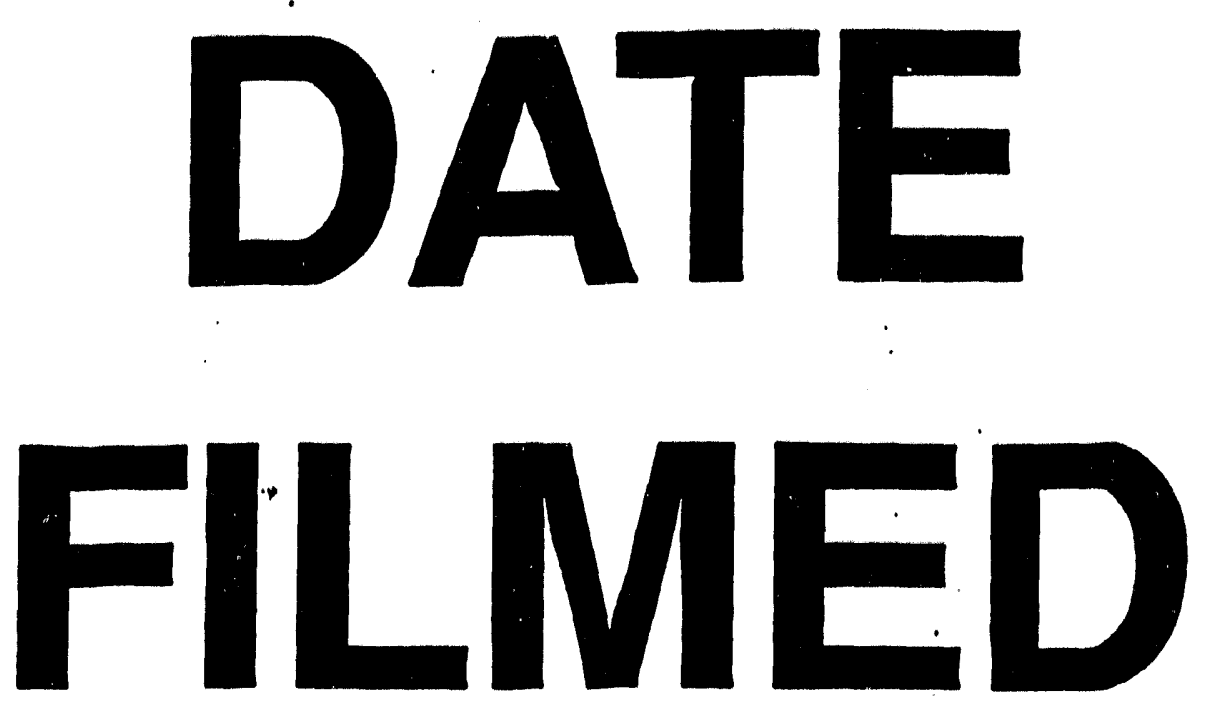

$12 / 27 / 93$
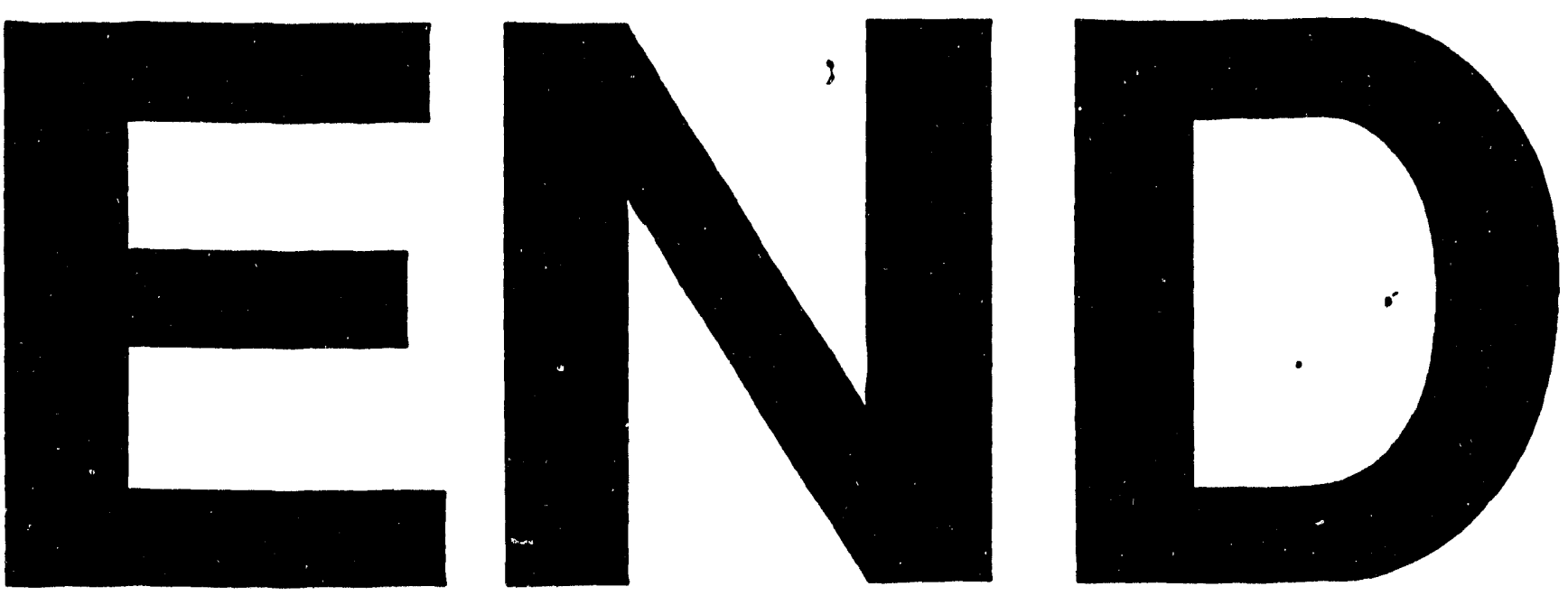
